\title{
Obesity-associated insulin resistance is correlated to adipose tissue vascular endothelial growth factors and metalloproteinase levels
}

Francisco José Tinahones ${ }^{1,2,3+}$, Leticia Coín-Aragüez ${ }^{1,2+}$, Maria Dolores Mayas ${ }^{1,2}$, Eduardo Garcia-Fuentes ${ }^{1,2}$, Carmen Hurtado-del-Pozo ${ }^{4}$, Joan Vendrell ${ }^{5}$, Fernando Cardona ${ }^{1,3}$, Rosa-Maria Calvo ${ }^{4}$, Maria-Jesus Obregon ${ }^{4}$ and Rajaa El Bekay ${ }^{1,2^{*}}$

\begin{abstract}
Background: The expansion of adipose tissue is linked to the development of its vasculature, which appears to have the potential to regulate the onset of obesity. However, at present, there are no studies highlighting the relationship between human adipose tissue angiogenesis and obesity-associated insulin resistance (IR).

Results: Our aim was to analyze and compare angiogenic factor expression levels in both subcutaneous (SC) and omentum $(\mathrm{OM})$ adipose tissues from morbidly obese patients $(n=26)$ with low $(\mathrm{OB} / \mathrm{L}-\mathrm{IR})$ (healthy obese) and high $(\mathrm{OB} / \mathrm{H}-\mathrm{IR})$ degrees of $\mathrm{IR}$, and lean controls $(n=17)$. Another objective was to examine angiogenic factor correlations with obesity and IR.

Here we found that VEGF-A was the isoform with higher expression in both OM and SC adipose tissues, and was up-regulated 3-fold, together with MMP9 in OB/L-IR as compared to leans. This up-regulation decreased by $23 \%$ in OB/-H-IR compared to OB/L-IR. On the contrary, VEGF-B, VEGF-C and VEGF-D, together with MMP15 was downregulated in both $\mathrm{OB} / \mathrm{H}-\mathrm{IR}$ and $\mathrm{OB} / \mathrm{L}-\mathrm{IR}$ compared to lean patients. Moreover, MMP9 correlated positively and VEGFC, VEGF-D and MMP15 correlated negatively with HOMA-IR, in both SC and OM.

Conclusion: We hereby propose that the alteration in MMP15, VEGF-B, VEGF-C and VEGF-D gene expression may be caused by one of the relevant adipose tissue processes related to the development of $I R$, and the up-regulation of VEGF-A in adipose tissue could have a relationship with the prevention of this pathology.
\end{abstract}

Keywords: Vascular Endothelial Growth Factor and Metalloproteinase, Obesity, Insulin Resistance, Omentum Adipose Tissue, Subcutaneous Adipose Tissue

\section{Background}

The prevalence of obesity has increased dramatically in the last decades and is now considered a major health problem. In fact, the current epidemic of obesity has been suggested as the leading cause for the decreased life expectancy forecast for the next generation. Obesity is very often accompanied by other diseases, the most common being type 2 diabetes mellitus (T2DM) and cardiovascular complications [1-3].

\footnotetext{
* Correspondence: elbekay@gmail.com

+ Contributed equally

'CIBER Fisiopatología Obesidad y Nutrición (CB06/03), Instituto de Salud

Carlos III, Madrid, Spain

Full list of author information is available at the end of the article
}

T2DM and obesity both involve genetic and environmental factors. However, progression to overt diabetes in patients with obesity is not clearly predicted. Likewise, while some obese individuals progress to T2DM, others only have mild metabolic abnormalities suggesting that the absolute amount of fat stored may not be the most important factor in determining the relationship between obesity and T2DM [4-7].

Adipose tissue expandability in response to positive energy balance has traditionally been considered an adaptive passive process. However, recent evidence suggests that the expandability of adipose tissue is not an unlimited process. In fact, adipose tissue expandability may be an important factor determining the appearance of

\section{Ciomed Central}


obesity-associated co-morbidities [7-9]. Several studies have shown the prevalence of a negative IR status and no complications in patients with severe morbid obesity (Metabolically healthy, but obese individuals) [10-12].

Adipose tissue expansion is well known to be linked to the development of its vasculature [13]. Furthermore, it has been described that obesity is associated with extensive modifications in adipose tissue involving adipogenesis, angiogenesis and proteolysis [14]. However, until now, no studies have established the relationship between adipose tissue angiogenic capacity, obesity and IR.

It is generally well known that the vascular endothelial growth factor (VEGF) system accounts for most of the angiogenic activity in adipose tissue [15]. VEGF-A (17$23 \mathrm{kDa}$ ) is a major angiogenic factor that stimulates proliferation and migration of ECs [16]. $V E G F-B(21 \mathrm{kDa})$ is $43 \%$ identical to $V E G F-A$; it also promotes angiogenesis and is implicated in extracellular matrix (ECM) degradation via the regulation of plasminogen activation [17]. $V E G F-C$ displays a $30 \%$ homology with $V E G F-A$, and plays an important role in both angiogenesis and lymphangiogenesis [18,19]. VEGF-D is $48 \%$ identical to $V E G F-C$ and also promotes the growth of lymphatic vessels [20]. Matrix metalloproteinases (MMPs) are essential for proper ECM remodeling, a process that takes place during obesity-mediated adipose tissue formation. The development of obesity is associated with coordinated cellular processes, including adipocyte hypertrophy followed by recruitment of adipocyte precursors, and new fat cell differentiation [21,22]. These processes are also accompanied by neovascularization, essential for the generation and proper function of adipose tissue [23]. It is generally accepted that such multiple events include dynamic changes of cell-matrix interactions and extensive ECM remodeling, and that modifications in proteolytic activities within the adipose microenvironment might occur during the development of the fat depot. Among enzymes implicated in the degradation of matrix molecules and in the generation of bioactive factors, the matrix metalloproteinase family is considered to be primarily responsible for these processes [24]. These subgroups are collagenases, gelatinases, stromelysins, membrane-type MMPs (MT-MMPs), and other MMPs [25,26]. MMPs participate in many physiological and pathological processes such as embryonic development, angiogenesis, wound repair, reproductive cycling, and metastasis [24,25]. Also, they can mediate the release and/or activation of sequestered growth factors, including VEGFs, and the cleavage of cell surface adhesion receptors [25].

On the basis of all these antecedents our aim was to analyze angiogenic factor and metalloproteinases expression levels in adipose tissue from control and obese subjects with or without IR, to study the relationship between adipose tissue-angiogenic factors/metalloproteinase, obesity and IR.

\section{Results \\ Anthropometric and biochemical characteristics of the patients}

The anthropometric and biochemical parameters from controls and obese subjects (with low and with high insulin resistance) are depicted in Table 1 . The severely obese patient group had a significantly higher body mass index (BMI) and waist circumference (WC) $(57.27 \pm 2.07 \mathrm{~kg} / \mathrm{m} 2$ and $144.4 \pm 7.14)(p<0.05$ and $p<0.01$ respectively) with respect to lean subjects (Controls). No anthropometric differences were observed between the two groups of obese subjects with low and high degrees of insulin resistance. Table 1 also illustrates the biochemical abnormalities associated to obesity and IR, showing low levels of HDL cholesterol in morbidly obese patients as compared to lean subjects. Adiponectin, a protein hormone produced and secreted by adipocytes and known to regulate the metabolism of lipids and glucose and related to angiogenesis in adipose tissue showed significantly low levels in obese patients $(p<0.01)$. There were no differences in the homeostasis model assessment (HOMA) indices between healthy OB/L-IR and controls, and both groups in turn displayed significant differences in this index respect to the $\mathrm{OB} / \mathrm{H}$-IR group.

\section{Angiogenesis related gene expression profiles in $\mathrm{OM}$ and SC adipose tissues from leans, OB/H-IR and OB/L-IR subjects}

We performed mRNA expression analysis in a set of genes involved in the regulation of angiogenesis in OM and SC samples from lean and obese subjects both with low and high degrees of IR. These genes are basically VEGF isoforms and proteolytic MMPs. Figure 1A shows that $V E G F-A$ gene expression was significantly enhanced in $\mathrm{OM}$ from $\mathrm{OB} / \mathrm{L}-\mathrm{IR}$ (by about 3 fold) as compared to lean subjects. VEGF-A gene expression up-regulation was significantly reduced by about $23 \%$ in $\mathrm{OB} / \mathrm{H}-\mathrm{IR}$ subjects as compared to OB/L-IR. In SC, VEGF- $A$ levels were lower than those observed in $\mathrm{OM}$, however the up-regulation of this angiogenic form was also observed in both OB/L-IR and $\mathrm{OB} / \mathrm{H}-\mathrm{IR}$ subjects compared to leans. These data indicate the high up-regulation of VEGF- $A$ isoform in both SC and $\mathrm{OM}$ adipose tissues from healthy morbidly obese subjects and this up-regulation was diminished in morbidly obese subjects with IR.

However, VEGF-B gene expression was significantly down-regulated in both OM and SC from OB/H-IR and $\mathrm{OB} / \mathrm{L}-\mathrm{IR}$ subjects compared to leans, and no significant differences were observed between $\mathrm{OB} / \mathrm{H}-\mathrm{IR}$ and $\mathrm{OB} / \mathrm{L}-$ IR subjects. Both VEGF-C and VEGF-D gene expressions 
Table 1 Clinicopathological characteristics and biomarker parameters

\begin{tabular}{lllll}
\hline & Control $(\mathbf{n}=\mathbf{1 7})$ & OB/non IR $(\mathbf{n}=\mathbf{1 2})$ & OB/H-IR $(\mathbf{n}=\mathbf{1 4})$ & $\boldsymbol{p}$ \\
\hline Age (years) & $44.46 \pm 2.2^{\mathrm{a}}$ & $43.64 \pm 3.22^{\mathrm{a}}$ & $37.50 \pm 2.90^{\mathrm{a}}$ & - \\
\hline BMI & $23.04 \pm 0.32^{\mathrm{a}}$ & $57.28 \pm 2.40^{\mathrm{b}}$ & $57.26 \pm 1.75^{\mathrm{b}}$ & $<0.05$ \\
\hline Triglycerides $(\mathbf{m M})$ & $1.14 \pm 0.15$ & $1.19 \pm 0.15$ & $1.13 \pm 0.36$ & - \\
\hline HOMAindex & $1.23 \pm 0.14^{\mathrm{a}}$ & $3.31 \pm 0.24^{\mathrm{a}}$ & $13.79 \pm 1.28^{\mathrm{b}}$ & $<0.01$ \\
\hline Adiponectin $(\boldsymbol{\mu} \mathbf{g} / \mathbf{m L})$ & $12.48 \pm 1.26^{\mathrm{a}}$ & $10.83 \pm 1.54^{\mathrm{b}}$ & $9.07 \pm 1.52^{\mathrm{b}}$ & $<0.01$ \\
\hline Cholesterol $(\mathbf{m M})$ & $4.91 \pm 0.29^{\mathrm{a}}$ & $5.38 \pm 0.45^{\mathrm{a}}$ & $5.02 \pm 0.19^{\mathrm{a}}$ & - \\
\hline Cholesterol HDL $(\mathbf{m M})$ & $1.42 \pm 0.14 \mathrm{a}$ & $0.93 \pm 0.20^{\mathrm{b}}$ & $1.04 \pm 0.12^{\mathrm{b}}$ & 0.05 \\
\hline Waist circumference & $82.03 \pm 1.95$ & $142.8 \pm 6.88$ & $146.0 \pm 7.41$ & $<0.01$ \\
\hline
\end{tabular}

Data are mean \pm SEM. BMI: body mass index, HOMA index: homeostasis model assessment index. Comparison of high degree insulin resistant $(O B / H-I R)$ and low degree insulin resistant $(O B / L-I R)$ obese subjects versus controls was assessed by ANOVA test. Groups with different letters showed significant differences.

showed a drastic and significant down-regulation in both $\mathrm{OM}$ and $\mathrm{SC}$ from $\mathrm{OB} / \mathrm{H}-\mathrm{IR}$ and $\mathrm{OB} / \mathrm{L}-\mathrm{IR}$ subjects compared to leans. Moreover, VEGF- B, VEGF-C and VEGF$D$ expression levels were much lower in both $\mathrm{OM}$ and $\mathrm{SC}$ as compared to VEGF-A isoforms.

$V E G F$ isoform protein expressions were also analyzed in both OM and SC from leans and OB/H-IR and OB/L-IR subjects. Figure $1 \mathrm{~B}$ shows evidence for the presence of protein synthesis of the four VEGF isoforms in both OM and $\mathrm{SC}$ in all the subjects. These protein analyses confirmed the results obtained by real time PCR, showing that $V E G F-A$ is the isoform more abundant in both OM and $\mathrm{SC}$ as compared to the other isoforms, and that this isoform is especially enhanced in obese subjects compared to leans. In addition, we observed that VEGF-B, VEGF-C and $V E G F-D$ protein expression was decreased in obese subjects compared to leans, especially in those with high degrees of insulin resistance (Figure 1B).

MMP9 gene expression levels were significantly enhanced especially in SC from both OB/H-IR and OB/LIR subjects compared with leans (Figure $1 C$ ). In fact, in OM, MMP9 expression was about $25 \%$ higher in OB/L-IR subjects than in leans, and about $50 \%$ higher in OB/H-IR compared to leans. In SC, the differences in MMP9 gene expression were even higher than in OM. In fact, SC $M M P 9$ gene expression was 3-fold higher in OB/L-IR subjects than in leans, and about 6-fold higher in OB/H-IR subjects than in leans. When comparing SC MMP9 gene expression in the two obese groups, its expression was $80 \%$ higher in OB/H-IR subjects than in OB/L-IR (Figure 1C). Opposite, MMP15 expression showed significant downregulation in both OM and SC from both OB/H-IR and OB/L-IR subjects compared to leans (Figure 1C). In fact, OM MMP15 gene expression was lower by approximately $50 \%$ in OB/H-IR and OB/L-IR subjects compared to leans, and this difference was statistically significant. Also, SC MMP15 gene expression levels were approximately 33\% lower in OB/L-IR subjects than in leans and by about $40 \%$ lower in OB/H-IR compared to leans.

\section{Correlation analysis with HOMA and IR}

Correlation analysis of the different genes studied with HOMA, the parameter determining the subjects' insulin resistance indicated that $V E G F-C$ and $V E G F-D$ from both $\mathrm{SC}$ and $\mathrm{OM}$ correlated negatively with the HOMA index (Figure 2A-D). Nevertheless, when we examined the correlation between VEGF-A and HOMA, no correlations was observed in both OM and SC. Moreover, we observed that MMP9 metalloproteinase correlated positively with HOMA (Figure 2E and 2F). However, MMP15 showed a clear negative correlation with HOMA in both SC and OM tissues (Figure $2 \mathrm{G}$ and $2 \mathrm{H}$ ). On the other hand, when we analyzed the correlations between $V E G F$ isoforms and the $M M P s$ we noted that MMP15 correlates positively with VEGF-C $(\mathrm{r}=0.53, p<0.02)$. MMP9 showed a significant negative correlation with VEGF-C $(\mathrm{r}=-0.48, p<$ $0.05)$, and positive correlation with VEGF-A $(\mathrm{r}=0.33, p<$ $0.05)$. Moreover, analyzing the potential correlations between $V E G F$ isoforms, we observed a positive and significant correlation between VEGF-C and VEGF-B $(\mathrm{r}=$ $0.60, p<0.05)$ and between VEGF-C and VEGF-D $(\mathrm{r}=$ $0.77, p<0.001)$. However, no significant correlation was observed between $V E G F-A$ and others $V E G F$ isoforms. On the other hand, when we analyzed the correlations between these angiogenic parameters and HOMA index in obese group, we observed that the results showed the same trends as in above statistical analysis, although some correlations did not show significant differences (Table 2)

\section{Discussion}

Modulation of angiogenesis can potentially impair the development of obesity-associated co-morbidities. However, little is known of the relationship between angiogenic components and insulin resistance in human adipose tissues.

The fact that some morbidly obese subjects having VEGF-A overexpressed in their adipose tissue did not develop IR leads us to believe that the enhancement of VEGF-A, which is known be responsible for most of 

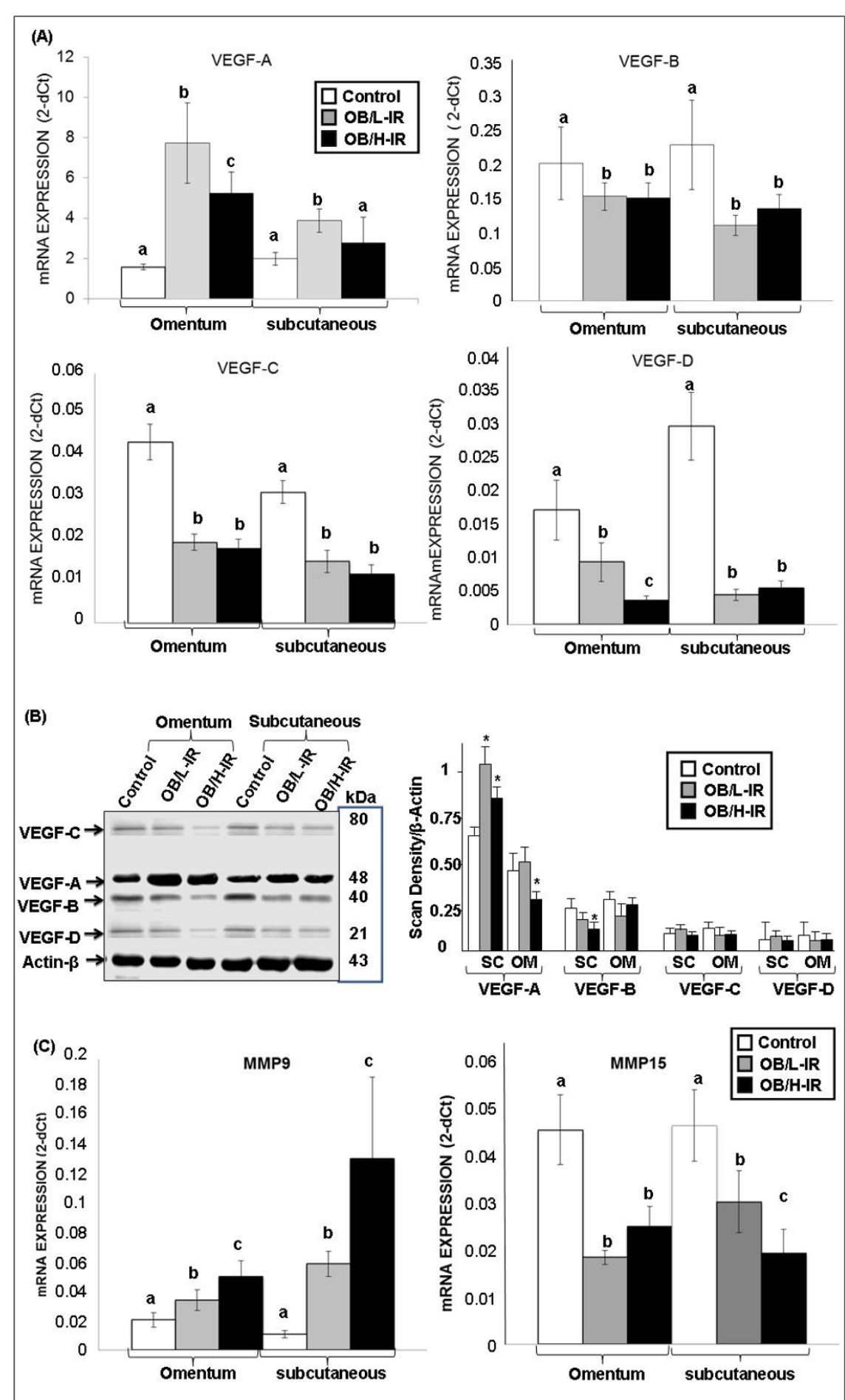

Figure 1 VEGF isoforms, MMP9, MMP15 mRNA and protein expression in omentum and subcutaneous AT from subjects. (A) VEGF isoforms [VEGF-A, VEGF-B, VEGF-C and VEGF-D] mRNA expression analysis was performed on human omentum (OM) and subcutaneous (SC) adipose tissues from three subject groups (lean, OB/H-IR and OB/L-IR subjects). mRNAs were normalized to cyclophilin levels. Results were obtained from triplicate and expressed as the mean \pm SEM ( $n=17$ for controls, $n=12$ for OB/L-IR and $n=14$ for OB/H-IR). Bars with different letters have a significant difference, $p<0.05$. (B) Immunoblotting analysis of VEGF isoforms. The resulted blot of each isoform was compared to Actin- $\beta$ constitutive protein. Density analyze was done normalizing the samples to $\beta$-actin using NIH's Image-J software program. The blot is representative of three independent experiments with different samples, ${ }^{*} p<0.05$. (C) Metalloproteinase (MMP9 and MMP15) mRNA expression analysis was performed on human omentum (OM) and subcutaneous (SC) adipose tissues from three groups of subjects (leans, OB/H-IR and OB/ L-IR). mRNAs were normalized to cyclophilin levels. Bars with different letters have a significant difference $(p<0.05)$; differences are compared to the control and between the two groups of obese. 

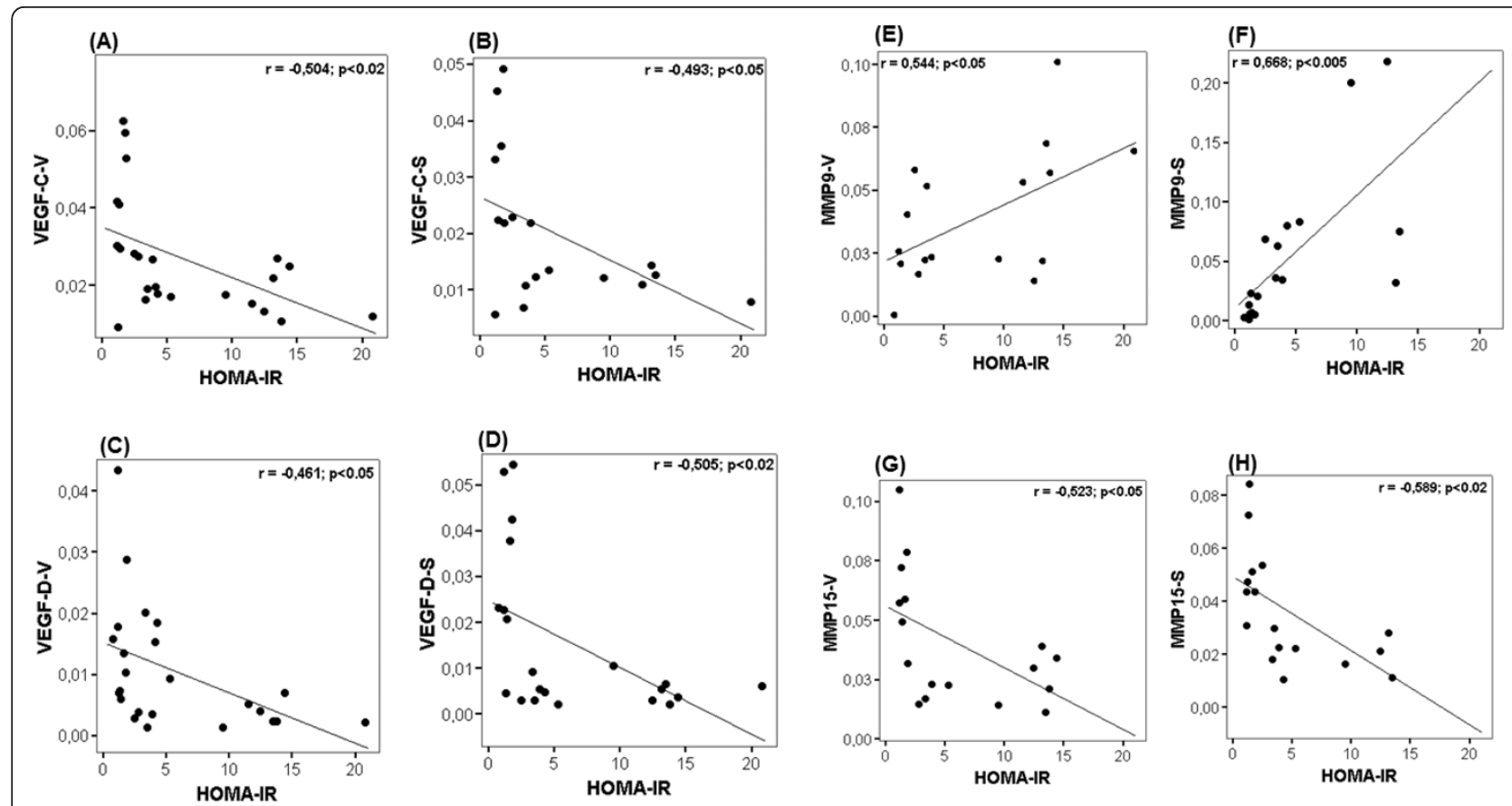

Figure 2 Correlative analysis of VEGF isoforms and MMPs with the HOMA index. Correlation of VEGF-C and VEGF-D isoforms, MMP15 and MMP9 mRNA expression with the HOMA index from both omentum (OM) and subcutaneous (SC) adipose tissues was determined by Pearson's correlation coefficient test $(r)$.

adipose tissue's angiogenic capacity [26], could probably be in response to the impaired lymphangiogenic capacity, which was reflected by VEGF-B, VEGF-C and VEGF-D reduction. These mechanisms may somehow have some relationship in preventing IR. In line with our findings, it has been recently described that during differentiation of 3 T3-F442A preadipocytes, VEGF-B and VEGF-C mRNA levels are less modulated, whereas that of VEGF-A are up-regulated [27]. Moreover, other data show that in patients with abdominal obesity, stimulation of SAT angiogenesis associated to insulin resistance promotes SAT hyperplasia, thus enhancing the storage capability of adipose tissue [28]. Our suggestions may appear speculative, but we consider that the significant negative correlation of VEGF-C and VEGF-D

Table 2 Correlations between VEGF isoforms and MMPs gene expression with HOMA-IR in adipose tissue from obese subjects

\begin{tabular}{lll}
\hline & Rs & $\boldsymbol{p}$ \\
\hline VEGF-C-V/HOMA IR & -0.404 & 0.054 \\
\hline VEGF-C-S/HOMA IR & $-0.412^{*}$ & 0.036 \\
\hline VEGF-D-V/HOMA IR & $-0.403^{*}$ & 0.021 \\
\hline MMP9-V/HOMA IR & $0.439^{*}$ & 0.041 \\
\hline MMP9-S/HOMA IR & 0.417 & 0.052 \\
\hline MMP15-S/HOMA IR & -0.357 & 0.0652 \\
\hline
\end{tabular}

Correlations were determined by Pearson's correlation coefficient test ${ }^{*} p<0.05$. with the HOMA index points to the possible relationship between down regulation of these two isoforms and insulin resistance development in morbidly obese subjects. Our hypothesis is that down-regulation of these angiogenic factors could be related to an alteration in the insulin sensitivity signaling pathway, as it is well known that insulin sensitivity signaling pathways involve a variety of genes including VEGF, GLUT1 and hypoxiainducible factor HIF-1 $\alpha /$ ARNT [29].

MMPs are proteolytic enzymes that play an essential role in extracellular matrix remodeling and VEGF regulation. MMPs are involved in two important events of this process and control proteolysis and adipogenesis during obesity-mediated fat mass development [30,31]. Several previous studies have suggested a role for MMPs in adipose tissue remodeling. Other studies have reported altered levels of MMPs in disorders related to insulin resistance [32]. Here, the up-regulation of gene expression of MMP9 and its positive correlation with the HOMA index point to the potential relationship between this metalloproteinase and insulin resistance development in morbidly obese subjects. In accordance with our suggestions, recent studies showed that MMP-9 expression in adipose tissue is increased with obesity and insulin resistance and is increased in adipocytes, and this increase in MMP-9 was related to the regulation of mediators of insulin signaling pathways such as PKC $\alpha$ and PPAR $\gamma$ [33]. Other researchers have provided the first 
evidence that human adipose tissue releases MMP-9 and that this secretion is modulated during adipocyte differentiation [34]. Recent studies have also shown that MMP9 expression was elevated in preadipocytes and the stroma vascular fraction of obese subjects compared with those of non-obese subjects [35].

We can say that we are the first to evaluate MMP-15 in adipose tissue and to propose the potential relationship between it, obesity and insulin resistance. Down regulation of gene expression MMP-15 and its significant negative correlation with the HOMA index point to the existence of a potential relationship between this metalloproteinase, VEGF-C, VEGF-D and insulin resistance in morbidly obese subjects.

\section{Conclusions}

In summary, our study highlights a group composed by the angiogenic factor VEGF-A and a relevant regulator of ECM degradation, MMP9, which in our opinion, could be acting together in adipose tissue as a compensatory mechanism that replaces the alteration in VEGF-B, VEGF-C, VEGF-D and MMP15. These data add another fact related to the metabolic derangements of obesity, including IR to the disturbance of one of the functionalities of adipose tissue controlled by VEGF and metalloproteinase angiogenic factors factors.

Finally, we believe that a better understanding of the regulation of the expression of these angiogenic components in adipose tissue will thus be instrumental in the development of specific therapeutic targeting approaches.

\section{Methods}

Patients and adipose tissue collection

The study was performed in morbidly obese patients $(\mathrm{n}=26)$ undergoing bariatric surgery at the Hospital Clínico Virgen de la Victoria. Exclusion criteria were: T2DM treated with insulin, cardiovascular disease in the 6 months prior to inclusion in the study, evidence of acute or chronic inflammatory disease, infectious disease or the patient's decision not to participate in the study.

Control subjects $(n=17)$ were patients who underwent laparoscopic surgery for hiatus hernia or cholelithiasis, who were not obese, with a similar age to the morbidly obese group, and with the same selection criteria.

The study groups were organized by:

- Morbidly obese: High insulin resistance (HOMA IR $>9)$ shown in the text as (OB/H-IR). Low insulin resistance (HOMA IR $<4$ ) shown in the text as $(\mathrm{OB} /$ L-IR). The cut-off was set at average plus two standard deviations of the values of a healthy control population.

- Controls: BMI 18.5-24.9 without insulin resistance
All participants gave their informed consent, and the study was reviewed and approved by the ethics and research committee of the Vírgen de la Victoria Clinical University Hospital (Malaga, Spain).

Both SC and OM adipose tissues were obtained at the beginning of the surgical procedure and were stored immediately at $-80^{\circ} \mathrm{C}$.

\section{RNA extraction}

Total RNA was isolated from adipose tissue using the Trizol RNA isolation method (Invitrogen, Carlsbad, CA) and purified with the RNeasy Lipid kit (QIAGEN -Ref. 74804-, Valencia, CA).

\section{Real-time PCR}

Amplifications were performed using a MicroAmp ${ }^{\circledR}$ Optical 96-well reaction plate (PE Applied Biosystems) on an ABI 7500 Real-Time PCR System (Applied Biosystems). RT qPCR reactions were carried out for all genes using specific TaqMan ${ }^{\circledR}$ Gene Expression Assays. During PCR, the Ct values for each amplified product were determined using a threshold value of 0.1 . The specific signals were normalized by constitutively expressed cyclophilin (Cyc: Ref. 4326316E) signals using the formula $2^{-\Delta \mathrm{Ct}}$.

\begin{tabular}{|c|c|c|}
\hline \multicolumn{3}{|c|}{ TaqMan ${ }^{\circledR}$ gene expression assay probes } \\
\hline$V E G F-A: \quad$ Ref. & Hs00173626_m1. & Sequence: \\
\hline NM_001025366.2 & & \\
\hline $\begin{array}{l}\text { VEGF-B: Ref. } \\
\text { NM_003377.3 }\end{array}$ & Hs00957984_m1. & Sequence: \\
\hline $\begin{array}{l}\text { VEGF-C: Ref. } \\
\text { NM_005429.2 }\end{array}$ & Hs00153458_m1. & Sequence: \\
\hline $\begin{array}{l}V E G F-D: \quad \text { Ref. } \\
\text { NM_004469.4 }\end{array}$ & Hs01128659_m1. & Sequence: \\
\hline $\begin{array}{l}\text { MMP9: } \quad \text { Ref. } \\
\text { NM_004994.2 }\end{array}$ & Hs00234579_m1. & Sequence: \\
\hline $\begin{array}{l}\text { MMP15: Ref. } \\
\text { NM_002428.2 }\end{array}$ & Hs00233997_m1. & Sequence: \\
\hline
\end{tabular}

\section{Western blot analysis}

Total proteins from adipose tissues were extracted by NE-PER Nuclear and Cytoplasmatic Extraction Reagents protocol (Pierce -Ref.78833-). Protein extracts (30 $\mu \mathrm{g})$ were separated by SDS-PAGE, blotted onto a PVDF membrane and then incubated with specific antibodies (VEGF (A-20): sc-152; VEGF-B (J-14I): sc-80442; VEGF-C (H-48): sc-25783; VEGF-D (X142): sc-80447; Santa Cruz Biotechnology, INC. Monoclonal Anti-B-Actin: A5316; Sigma Aldrich). Protein signals were detected by electrochemiluminescence detection Quantity One ${ }^{\circledR}$ software (Bio-Rad Laboratories). 


\section{Statistical analysis}

SPSS Inc. software (Version 15.0) was used for all statistical analyses. Comparisons between the normalized mRNA levels of different genes and the biochemical characteristics of the groups used in this study were made by ANOVA test and the statistical differences between the groups were made by Duncan's test. The correlation analysis of mRNA quantitative expression of each of the genes was performed with Pearson's coefficient Test $(r)$.

\section{Acknowledgements}

This work was supported in part by grants from the Andalusian Health Service [SAS PI-0251], from Fondos de Investigación Sanitaria PS09/00997, Instituto Carlos III, from Incentivos a Proyectos de Excelencia p08-CTS-04369. Consejería de Innovación, Junta de Andalucía, and Rajaa El Bekay is recipient of a post-doctoral grant "Miguel Servet" (FIS-2007) (CP07/00288) from the Spanish Ministry of Health; and part of this project was supported by a grant from the Spanish Ministry of Health (FIS) (PI070953), and from Plan Nacional (MEC) SAF2009-09364 and S2010-BMD-2423 from Comunidad de Madrid. CIBEROBN is an initiative of ISCIII (Instituto de Salud Carlos III), Spain. The authors thank technician Juan Alcaide for his technical support in developing our laboratory techniques, and D.W.E. Ramsden for the manuscript revision. The authors also thank the endocrinology service of the Hospital Vírgen de la Victoria of Malaga.

\section{Author details}

${ }^{1}$ CIBER Fisiopatología Obesidad y Nutrición (CB06/03), Instituto de Salud Carlos III, Madrid, Spain. 'Laboratorio de Investigación Biomédica, Hospital Clínico Universitario Virgen de la Victoria, Campus de Teatinos s/n, 29010 Málaga, Spain. ${ }^{3}$ Servicio de Endocrinología, Hospital Virgen de la Victoria, Malaga, Spain. ${ }^{4}$ Instituto de Investigaciones Biomedicas (IIBM, CSIC-UAM]), Madrid, Spain. ${ }^{5}$ CIBERDEM. University Hospital of Tarragona Joan XXIII. IISPV, Rovira i Virgili University, Tarragona, Spain.

\section{Authors' contributions}

FJT financed part of the study, participated in the design of the study and helped to draft the manuscript, LCA and MDM carried out the molecular biology studies, EGF helped coordinate and collect samples from patients, CHDP, RMC, JV and FC participated in the molecular biology studies, and MJO participated in the molecular biology studies and financed part of the study. REB conceived, designed and coordinated the study, performed the statistical analysis and drafted the manuscript. All authors read and approved the final manuscript.

\section{Competing interests}

The authors declare that they have no competing interests.

Received: 11 August 2011 Accepted: 2 April 2012

Published: 2 April 2012

\section{References}

1. Bjorntorp P: Metabolic implications of body fat distribution. Diabetes Care 1991, 14:1132-1143.

2. Reaven G: All obese individuals are not created equal: insulin resistance is the major determinant of cardiovascular disease in overweight/obese individuals. Diab Vasc Dis Res 2005, 2:105-112.

3. Colquitt JL, Picot J, Loveman E, Clegg AJ: Surgery for obesity. Cochrane Database Syst Rev 2009, 2:CD003641.

4. Macias-Gonzalez M, Moreno-Santos I, García-Almeida JM, Tinahones FJ, Garcia-Fuentes E: PPARgamma2 protects against obesity by means of a mechanism that mediates insulin resistance. Eur J Clin Invest 2009, 39(11):972-979.

5. Despres JP, Lemieux I: Abdominal obesity and metabolic syndrome. Nature 2006, 444:881-887.

6. Blüher M: The distinction of metabolically 'healthy' from 'unhealthy' obese individuals. Curr Opin Lipidol 2010, 21(1):38-43.
7. Hanson RL, Imperatore $\mathrm{G}$, Bennett PH, et al: Components of the 'metabolic syndrome' and incidence of type 2 diabetes. Diabetes 2010, 51:3120-3127.

8. Tan CY, Vidal-Puig A: Adipose tissue expandability: the metabolic problems of obesity may arise from the inability to become more obese. Biochem Soc Trans 2008, 36(Pt5):935-940.

9. Rocha VZ, Libby P: Obesity, inflammation, and atherosclerosis. Nat ReV Cardiol 2009, 6(6):399-409.

10. Karelis AD, St-Pierre DH, Conus F, et al: Metabolic and body composition factors in subgroups of obesity: what do we know? J Clin Endocrinol Metab 2004, 89(6):2569-2575.

11. Soverini V, Moscatiello S, Villanova N, et al: Metabolic Syndrome and Insulin Resistance in Subjects with Morbid Obesity. Obes Surg 2010, 20(3):295-301.

12. Wildman RP, Muntner P, Reynolds K, et al: The Obese Without Cardiometabolic Risk Factor Clustering and the Normal Weight With Cardiometabolic Risk Factor Clustering Prevalence and Correlates of 2 Phenotypes Among the US Population (NHANES 1999-2004). Arch Intern Med 2008, 168(15):1617-1624.

13. Ledoux S, Queguiner I, Msika S, Calderari S, Rufat P, Gasc JM, Corvol P, Larger E: Angiogenesis associated with visceral and subcutaneous adipose tissue in severe human obesity. Diabetes 2008, 57(12):3247-3257.

14. Christiaens V, Scroyen I, Lijnen HR: Role of proteolysis in development of murine adipose tissue. Thromb Haemost 2008, 99(2):290-294.

15. Hausman GJ, Richardson RL: Adipose tissue angiogenesis. J Anim Sci 2004, 82(3):925-934.

16. Carmeliet P, Ferreira V, Breier G, Pollefeyt S, Kieckens L, Gertsenstein M: Abnormal blood vessel development and lethality in embryos lacking a single VEGF allele. Nature 1996, 380:435-439.

17. Olofsson B, Korpelainen E, Pepper MS, Mandriota SJ, Aase K, Kumar V: Vascular endothelial growth factor B (VEGF-B) binds to VEGF receptor-1 and regulates plasminogen activator activity in endothelial cells. Proc Natl Acad Sci USA 1998, 95:11709-11714.

18. Joukov V, Pajusola K, Kaipainen A, Chilov D, Lahtinen I, Kukk E: A novel vascular endothelial growth factor, VEGF-C, is a ligand for the Flt4 (VEGFR-3) and KDR (VEGFR-2) receptor tyrosine kinases. EMBO J 1996, 15:290-298.

19. Karkkainen MJ, Haiko P, Sainio K, Partanen J, Taipale J, Petrova T: V: Vascular endothelial growth factor $C$ is required for sprouting of the first lymphatic vessels from embryonic veins. Nat Immunol 2004, 5:74-80.

20. Stacker SA, Caesar C, Baldwin ME, Thornton GE, Williams RA, Prevo R: VEGFD promotes the metastatic spread of tumor cells via the lymphatics. Nat Med 2001, 7:186-191.

21. Spiegelman BM, Flier JS: Obesity and the regulation of energy balance. Cell 2001, 104(4):531-543.

22. Ailhaud G, Grimaldi P, Négrel R: Cellular and molecular aspects of adipose tissue development. Annu Rev Nutr 1992, 12:207-233.

23. Crandall DL, Hausman GJ, Kral JG: A review of the microcirculation of adipose tissue: anatomic, metabolic, and angiogenic perspectives. Microcirculation 1997, 4:211-232.

24. Vu TH, Werb Z: Matrix metalloproteinases: effectors of development and normal physiology. Genes Dev 2000, 14(17):2123-2133.

25. Sternlicht MD, Werb Z: How matrix metalloproteinases regulate cell behavior. Annu Rev Cell Dev Biol 2001, 17:463-516.

26. Zhang QX, Magovern CJ, Mack CA, Budenbender KT, Ko W, et al: Vascular endothelial growth factor is the major angiogenic factor in omentum: mechanism of the omentum-mediated angiogenesis. J Surg Res 1997, 67(2):147-154.

27. Voros G, Maquoi E, Demeulemeester D, Clerx N, Collen D, Lijnen HR: Modulation of angiogenesis during adipose tissue development in murine models of obesity. Endocrinology 2005, 146:4545-4554.

28. Kim JY, van de Wall E, Laplante M, Azzara A, Trujillo ME, et al: Obesityassociated improvements in metabolic profile through expansion of adipose tissue. J Clin Invest 2007, 117:2621-2637.

29. Zelzer E, Levy Y, Kahana C, Shilo BZ, Rubinstein M, Cohen B: Insulin induces transcription of target genes through the hypoxia-inducible factor HIF1alpha/ARNT. EMBO J 1998, 17:5085-5094.

30. de Luca C, Olefsky JM: Inflammation and insulin resistance. FEBS Lett 2008, 582:97-105.

31. Boden G: Obesity and free fatty acids. Endocrinol Metab Clin North Am 2008, 37:635-646. 
32. Roberts CK, Won D, Pruthi S, Kurtovic S, Sindhu RK, et al: Effect of a shortterm diet and exercise intervention on oxidative stress, inflammation, MMP-9, and monocyte chemotactic activity in men with metabolic syndrome factors. J Appl Physiol 2006, 100:1657-1665.

33. Unal R, Yao-Borengasser A, Varma V, Rasouli N, Labbate C, et al: Matrix metalloproteinase-9 is increased in obese subjects and decreases in response to pioglitazone. J Clin Endocrinol Metab 2010, 95:2993-3001.

34. Bouloumie A, Sengenes C, Portolan G, Galitzky J, Lafontan M: Adipocyte produces matrix metalloproteinases 2 and 9: involvement in adipose differentiation. Diabetes 2001, 50:2080-2086.

35. Derosa G, Ferrari I, D'Angelo A, Tinelli C, Salvadeo SA, Ciccarelli L, Piccinni MN, Gravina A, Ramondetti F, Maffioli P, Cicero AF: Matrix metalloproteinase-2 and -9 levels in obese patients. Endothelium 2008, 15(4):219-224.

doi:10.1186/1472-6793-12-4

Cite this article as: Tinahones et al:: Obesity-associated insulin resistance is correlated to adipose tissue vascular endothelial growth factors and metalloproteinase levels. BMC Physiology 2012 12:4.

\section{Submit your next manuscript to BioMed Central} and take full advantage of:

- Convenient online submission

- Thorough peer review

- No space constraints or color figure charges

- Immediate publication on acceptance

- Inclusion in PubMed, CAS, Scopus and Google Scholar

- Research which is freely available for redistribution

Submit your manuscript at www.biomedcentral.com/submit
Ciomed Central 